\title{
ASPECTOS RELEVANTES DO INSTITUTO DA INVERSÃO DO ÔNUS DA PROVA
}

JOÃO ALBERTO MENDES BEZERRA JR. 


\title{
ASPECTOS RELEVANTES DO INSTITUTO DA INVERSÃO DO ÔNUS DA PROVA
}

\author{
João Alberto Mendes Bezerra Jr.'
}

\begin{abstract}
RESUMO
O presente trabalho pretende contribuir, ainda que minimamente, com o mundo jurídico, no que diz respeito ao instituto da inversão do ônus da prova, previsto no art. $6^{\circ}$, VIII do Código Brasileiro de Defesa do Consumidor, sob o enfoque do Direito Constitucional. Além de abordar o alcance dos requisitos impostos por esse dispositivo legal, o estudo trata do momento em que a inversão do ônus da prova deve ocorrer no processo civil, trazendo novas luzes a respeito, mormente como reforço à tese da regra de julgamento, que, ao invés de corresponder a uma violação do princípio constitucional do devido processo legal, fortalece-o dentro de nosso ordenamento jurídico.
\end{abstract}

\section{Palavras-chave:}

Consumidor. Ônus da prova. Inversão. Requisitos. Regra de julgamento. Devido processo legal.

\begin{abstract}
The current work intends to contribute, albeit modestly, with the juridical studies regarding burden of proof inversion institute, regulated by Brazilian Consumer Defense Code (Chapter 6, VIII), which is to be examined taking into account a constitutional outlook. Besides analyzing the range of legal conditions imposed by the aforementioned rule, the study examines the moment in witch the burden of proof inversion must take place in civil procedure, arising new ideas on the subject, mainly to reinforce judgment rule proposition, witch, instead of consisting in a violation of the constitutional principle of due process of law, fortifies such principle in Brazilian juridical order.
\end{abstract}

\section{Keywords:}

Consumer. Burden of proof. Inversion. Requirements. Judgment rule. Due process of law.

\footnotetext{
'Juiz Substituto do Estado do Tocantins, Especialista em Direito Constitucional pela Universidade Estadual Vale do Acaraú/Escola Superior da Magistratura do Estado do Ceará - ESMEC (e-mail: jrmendez@uol.com.br)
} 


\section{INTRODUÇÃO}

Direito é conduta em interferência intersubjetiva. Mas, pode ser entendido, em linguagem menos técnica, como proporcionalidade, reciprocidade. Assim como os elementos químicos que se ligam entre si para formar substâncias estáveis, o Direito também visa à estabilidade, ao equilíbrio. Fora disso, perde a sua razão de ser, desnatura-se. Não é sem razão que Dante Alighieri o definiu, magistralmente, como a "proporção real e pessoal, de homem para homem, que conservada, conserva a sociedade; corrompida, corrompe- $a$ ".

A esse propósito, o Processo, por sua vez, serve como uma engrenagem imprescindível e fundamental, considerado o escopo político de pacificação social. É o instrumento pelo qual, no Estado Democrático, se realiza a nobre função de dizer o direito, resolvendo os conflitos e, de conseguinte, apaziguando as partes, além de servir, igualmente, como uma garantia de manutenção daquele equilíbrio.

Com efeito, o Juiz, representando o Estado, substitui-se aos litigantes, dando, a cada um, o que é seu por meio da sentença, a qual deverá ser obrigatoriamente motivada, segundo os elementos constantes dos autos, a fim de que os interessados compreendam as razões do julgamento, podendo dele recorrer ou, simplesmente, se convencer da justiça da decisão, entregando, de bom grado, o bem da vida ao seu legítimo titular ou, conforme seja, restabelecendo situações anteriormente reconhecidas, o que constitui a finalidade maior do ordenamento jurídico como um todo.

O Direito Processual pátrio, portanto, adotou o princípio da persuasão racional, cabendo necessariamente ao Estado-Juiz, com isenção (leia-se: imparcialidade) e responsabilidade, procurar obter o convencimento das partes, através da motivação de seus atos (do Estado-Juiz), calcada no arcabouço probatório coligido aos autos, toda vez que a matéria disser respeito a fatos que imponham essa atividade judicante.

E, especificamente no Processo Civil -, que difere do Processo Penal, pois que ali vige o princípio da verdade formal -, o desafio, em matéria dé prova, é chegar o mais próximo possível da verdade real.

Não obstante, ainda é correto dizer que - e isso vale também 
para o Processo Penal-, o que se alcança é a verdade processual.

Assim, considerando que a verdade é uma só, como dizia Sócrates, em oposição aos Sofistas, a verdade processual, numa situação ideal, deve corresponder à verdade real.

Mas, não se vive no mundo das idéias referido por Platão. Ainda que o homem evolua a passos largos no caminho da perfeição, esta é apenas mais uma idéia que, ao lado de tantas outras, revela-se inatingível.

Depois de cerca de seis mil anos de história, o que se tem de mais paradigmático no Direito é a verdade processual, que subsiste dentro de um sistema de princípios e regras cuja finalidade precípua é o alcance da verdade real, mas com obediência a limites de toda ordem (até mesmo logística) impostos pela própria realidade prática, encontrando-se, o Direito, ele também, em perpétuo estado de aperfeiçoamento.

E, no Brasil, não poderia ser diferente. Em um momento em que se prioriza a efetividade da jurisdição (haja vista o princípio da razoável duração do processo, levado ao Texto Maior por obra e graça da Emenda Constitucional $n^{\circ} .45 / 2004$, que acrescentou o inc. LXXVIII ao seu art. $5^{\circ}$ ), até mesmo em detrimento da segurança jurídica, dês que os meios para garantir a celeridade de tramitação ainda são assustadoramente escassos, o que se tem, especialmente no Processo Civil, é um sistema onde a prova assume papel preponderante, constituindo a verdadeira alma do processo no seu desiderato de realização da justiça.

Com efeito, perceba-se que, em geral, toda pretensão está presa a um ou mais fatos pretéritos, podendo a afirmação desses fatos corresponder ou não à bendita verdade. Justamente para possibilitar a sustentação das alegações dos interessados, com vistas ao convencimento do julgador sobre a verdade do caso levado ao seu conhecimento, é que o Direito confere àqueles a oportunidade de realizarem provas.

Pois bem. O momento da prova, no Processo Civil brasileiro, compreende quatro etapas bem definidas, a saber: a) a da propositura, quando se protesta pela realização da prova (no desfecho da petição inicial e da contestação); b) a da admissão, que no procedimento comum ordinário ocorre no ambiente da audiência preliminar (CPC 331), em regra, deferindo ou não, o magistrado, a 
realização da prova requerida, depois da fixação dos pontos controvertidos da demanda e da especificação das provas protestadas $a b$ initio; c) a da produção, que se confunde com a própria instrução processual; d) a fase de valoração da prova, consistente no seu aproveitamento ou não para o convencimento do magistrado, o que se dá na prolação da sentença. A semelhança com as fases do processo (postulação, saneamento, instrução e julgamento) não é sem razão, já que, como dito, a prova é o centro do universo processual.

Obviamente que todas essas etapas encontram-se interligadas. Assim, para que seja valorada na sentença, é necessário que a prova, antes, tenha sido produzida, o que só acontece se tiver sido admitida e, primeiramente, é claro, requerida, seja pelo autor, na petição inicial, seja pelo réu, na contestação.

Daí que, se não houver a especificação de uma prova no momento oportuno, não se tratando de matéria de ordem pública, não poderá ser requerida posteriormente, perdendo, a parte, a oportunidade de produzi-la e, conseqüentemente, de mostrar a sua versão sobre determinado fato pretérito. Eis porque se fala, dentre outros exemplos e circunstâncias, em verdade processual.

4 Em suma, o que se quer dizer é que um pedido pode ser julgado improcedente, mesmo que existisse prova em sentido contrário e fosse do conhecimento da parte, a qual, todavia, por descuido, não chegou a ser produzida, ficando, pois, fora dos autos; assim como, de outra banda, a procedência da ação não fica condicionada à demonstração da verdade real, podendo-se alcançar esse resultado com arrimo em juízo de verossimilhança, e não necessariamente de certeza.

É exatamente no contexto do momento da prova, que se desenvolverá o tema aqui proposto, relacionado com a inversão do onus probandi; mais precisamente, na dinâmica da defesa do consumidor em juízo. Um direito que foi elevado à condição de valor constitucional, a partir do novel Estado, agora Democrático de Direito, instituído em 1988, e que se encontra expressamente estampado no inciso XXXII do art. $5^{\circ}$ da Carta Magna, com o seguinte teor: "O Estado promoverá, na forma da lei, a defesa do consumidor". Hoje, portanto, um direito fundamental, nada obstante constitua norma constitucional de eficácia limitada, conquanto 
dependesse de normatividade ulterior para a sua efetiva incidência.

E ela veio com a Lei $\mathrm{n}^{\circ}$. 8.078, de 11 de setembro de 1990: O Código de Defesa do Consumidor, que entrou em vigor 180 (cento e oitenta) dias depois de sua publicação.

Acontece que, no afã de tornar efetivo o direito fundamental à defesa do consumidor, o legislador ordinário mitigou princípios consagrados, tais como o de que "o ônus da prova incumbe a quem alega" e "alegar e não provar é o mesmo que não alegar".

Parece comezinho hoje, mas foi preciso o transcurso de vários séculos até que se consolidasse, entre os povos cultos, o entendimento consoante o qual aquele que afirma algo a respeito de outrem, ou acerca da esfera de interesses de terceiros, deve apontar as provas de suas afirmações, sob pena de elas não poderem, jamais, prevalecer: actore non probante, reus absolvitur. E uma questão de igualdade e justiça, valores mui caros para a civilização ocidental.

Daí surgirem inúmeros questionamentos de cunho constitucional, entre os quais se podem destacar: à luz do ordenamento constitucional brasileiro, é válida a mitigação de tão importantes princípios? O devido processo legal não estaria sendo vulnerado? Para que seja possível a inversão do ônus da prova, sem violar a Constituição da República, quais os limites de atuação do magistrado? Há um momento processual adequado para fazê-lo, a fim de preservar a constitucionalidade da medida?

As respostas a essas e outras perguntas constituem, em apertada síntese, o objeto do presente estudo.

\section{INVERSÃO DO ÔNUS DAPROVA}

\subsection{Espécies}

Esclareça-se, de plano, que o instituto da inversão, para boa parte da doutrina, já existia no ordenamento jurídico brasileiro, mas na forma convencional (bem assim na legal, o que será explicado em seguida), como se vê do parágrafo único do art. 333 da nossa Lei Adjetiva Civil, que trata da distribuição do onus probandi, expressis verbis:

Art. 333. O ônus da prova incumbe:

I- ao autor, quanto ao fato constitutivo do seu direito; 
II - ao réu, quanto à existência de fato impeditivo, modificativo ou extintivo do direito do autor.

Parágrafo único. É nula a convenção que distribui de maneira diversa o ônus da prova quando:

I- recair sobre direito indisponivel da parte;

II - tornar excessivamente dificil a uma parte o exercício do direito. (Grifou-se).

Sobre essa distribuição do ônus da prova, imputando ao réu, por seu turno, a demonstração da existência de fatos impeditivos, modificativos ou extintivos do direito do autor (CPC 333 II), diz-se tratar-se de inversão legal (ou ope legis), conquanto determinada pela própria lei (de que são exemplos, também, os arts. $12, \S 3^{\circ} ; 14, \S$ $3^{\circ}$ e 38 do CDC).

Cabe aqui, porém, a crítica, aventada por alguns, de que, em todos os casos acima referidos, não se estabelece propriamente uma inversão do ônus da prova, tratando-se, em verdade, de regras gerais (CPC 333) e especiais (CDC 38, v.g.) de sua distribuição, polêmica essa que não interessa ao estudo em questão, pelo que é deixada, propositalmente, de lado.

A inversão do ônus da prova por decisão judicial, contudo, é uma inovação trazida pelo Código de Defesa do Consumidor (para alguns, a única forma de inversão verdadeiramente estabelecida), que prescreve, no inc. VIII de seu art. $6^{\circ}$, o seguinte:

Art. $6^{\circ}$ São direitos básicos do consumidor:

'Omissis'

VIII - a facilitação da defesa de seus direitos, inclusive com a inversão do ônus da prova, a seu favor, no processo civil, quando, a critério do juiz, for verossímil a alegação ou quando for ele hipossuficiente, segundo as regras ordinárias de experiências:

(...). (Grifou-se).

Haveria, pois, no ordenamento processual civil pátrio três espécies de inversão do onus probandi, quais sejam: a legal (ope legis), a convencional e a judicial (ope judicis), constituindo, esta última, uma inovação introduzida pela Lei $n^{\circ}$. 8.078/1990.

Saliente-se que essa nova situação jurídica processual guarda estreita relação com o direito material, na medida em que a finalidade específica da norma é acabar com a vulnerabilidade do consumidor no tocante à demonstração dos fatos constitutivos de 
seu direito ${ }^{2}$.

Aqui, já se pode responder ao primeiro dos questionamentos lançados quando da parte introdutória deste estudo: à luz do ordenamento constitucional brasileiro, é válida a mitigação de tão importantes princípios?

Os princípios a que se refere o texto podem ser resumidos no brocardo latino allegare nihil et allegatum non probare paria sunt, ou seja, "alegar e não provar é o mesmo que não alegar", traduzindo a clássica idéia de que incumbe a quem alega o ônus de provar a alegação.

Trata-se de um princípio que realiza o valor igualdade, inscrito no texto das constituições de todos os povos cultos, eis que a exigência da prova neutraliza a força das vãs acusações. Daí a procedência daquela proposição (isto é, a resposta é sim), que em outras palavras põe em xeque a possibilidade de, ainda no plano abstrato da lei ordinária, o instituto da inversão do onus probandi enfraquecer o próprio princípio da isonomia.

Tal resposta pode parecer capciosa, mas a verdade é que o princípio da igualdade não sai enfraquecido com a disciplina do art. $6^{\circ}$, VIII do CDC. Ao contrário, se fortalece.

É que se vive uma nova realidade sócio-econômica, tangida pela globalização e a revolução tecnológica, nos planos interno e externo, sendo comum denominá-la sociedade de massas ou sociedade de consumo.

Nessa seara, os mecanismos de tutela conferidos pelo direito tradicional não mais ofereceriam a proteção desejada pelos lesados, sendo imperioso que se instituísse a facilitação da defesa dos consumidores em juízo.

Com isso, homenageia-se a igualdade substancial, em detrimento da igualdade meramente formal, robustecendo, como se disse, esse valor imanente ao próprio sentido de Constituição, pois que, sem uma igualdade real, material, resta completamente esvaziado o princípio da dignidade da pessoa humana

No que tange, pois, às relações jurídicas de consumo, disciplinadas pela Lei $\mathrm{n}^{\circ}$. 8.078/1990, observa-se uma nova

${ }^{2}$ DIDIER JR., Fredie (Org.). Leituras Complementares de Processo Civil, p. 25 ss. 
sistemática, que se afasta das diretrizes traçadas pelo art. 333 do $\mathrm{CPC}$, relativamente à distribuição do ônus da prova entre as partes do processo, em homenagem, precisamente, à isonomia material.

Com efeito, na esteira do processo civil comum, a fase de produção da prova se orienta por duas regras fundamentais: $1^{a}$ ) ao autor incumbe a prova do fato constitutivo de seu direito; $2^{\mathrm{a}}$ ) ao réu, cabe a prova acerca da existência de fato impeditivo, modificativo ou extintivo do direito daquele. Com o advento do CDC, porém -, que previu como direito básico do consumidor a facilitação de sua defesa, inclusive com a inversão (judicial) do ônus da prova a seu favor no processo civil, quando, a critério do juiz, for verossímil a alegação ou for ele hipossuficiente, segundo as regras ordinárias de experiência-, aquela sistemática teve a sua eficácia completamente relativizada.

\subsection{Requisitos (CDC $6^{\circ}$ VIII)}

Reza o texto legal, não custa repetir:

Art. $6^{\circ}$ São direitos básicos do consumidor:

'Omissis'

VIII - a facilitação da defesa de seus direitos, inclusive com a inversão do ônus da prova, a seu favor, no processo civil, quando, a critério do juiz, for verossímil a alegação ou quando for ele hipossuficiente, segundo as regras ordinárias de experiências:

(...). (Grifou-se).

Note-se, em primeiro lugar, que a inversão do ônus da prova, pela própria literalidade do preceito acima transcrito, é apenas um dos meios de facilitação da defesa dos direitos do consumidor.

Com efeito, ela não se apresenta como um instituto autônomo e isolado, fazendo parte, ao contrário, do contexto maior da ampla proteção outorgada aos consumidores em geral, que abrange desde o reconhecimento de sua vulnerabilidade no mercado, passando pela acessibilidade aos órgãos judiciários e administrativos - com vistas não só à reparação, mas também à prevenção dos danos -, até a própria responsabilização objetiva dos fornecedores. ${ }^{4}$

'KRIGER FILHO, Domingos Afonso. Inversão do ônus da prova: regra de julgamento ou de procedimento? p. 276.

Idem, p. 283.

Revista Esmat, Palmas, Ano 2, n², pag. 83 a 110 - jan/dez 2010 
Atente-se, por oportuno, como dito alhures, às restrições do objeto do presente trabalho. O que se quer dizer é que a defesa do consumidor, como direito fundamental, tem uma amplitude que ultrapassa em muito a discussão em tablado, a qual se sujeita à análise da proteção do consumidor em juízo, mas tão-somente no plano do processo civil e, especificamente, quanto ao instituto da inversão do ônus da prova, constituindo apenas um pequeno traço do direito (positivo) de proteção ao consumidor, embora enseje graves implicações.

De qualquer forma, o sucesso de todo o debate aqui proposto depende de uma análise mais aprofundada do instituto da inversão, o que só se mostra satisfatório quando estudados os elementos ou requisitos essenciais do objeto em exame.

Pois bem. Em uma interpretação meramente literal, vê-se que o juiz pode, em favor do consumidor, inverter o ônus da prova, a seu critério e segundo as regras ordinárias da experiência, desde que a) haja verossimilhança nas suas alegações ou b) seja ele hipossuficiente.

O primeiro obstáculo a ser transposto, pertinentemente à dicção da norma de que se cuida, é saber se os requisitos da verossimilhança das alegações e da hipossuficiência do consumidor são cumulativos ou alternativos.

Passando em revista a doutrina e a jurisprudência sobre o assunto, constata-se que, embora não haja consenso absoluto, a tendência é fortemente majoritária no sentido da alternatividade daqueles requisitos.

Pela doutrina, Cláudia Lima Marques pontifica: “... a partícula 'ou' bem esclarece que, a favor do consumidor, pode o juiz inverter o ônus da prova quando apenas uma das duas hipóteses está presente no caso. Não há qualquer outra exigência no CDC, sendo assim facultado ao juiz inverter o ônus da prova inclusive quando esta prova é difícil mesmo para o fornecedor, parte mais forte e expert na relação, pois o espírito do CDC é justamente de facilitar a defesa dos direitos dos consumidores e não o contrário, impondo provar o que é em verdade o 'risco profissional' ao - vulnerável e leigo consumidor. Assim, se o profissional coloca máquina, telefone ou senha à disposição do consumidor para que realize saques e este afirme de forma verossímil que não os realizou, a prova de quem 
realizou tais saques deve ser imputada ao profissional, que lucrou com esta forma de negociação, ou de execução automática, ou em seu âmbito de controle interno: cujus commodum, ejus periculum. Em outras palavras, este é o seu risco profissional e deve organizarse para poder comprovar quem realizou a retirada ou o telefonema. Exigir uma prova negativa do consumidor é imputar a este pagar duas vezes pelo lucro do fornecedor com atividade de risco no preço pago e no dano sofrido. Daí a importância do direito básico assegurado ao consumidor de requerer no processo a inversão do ônus da prova."

Considerando que a inversão do onus probandi envolve matéria fática, a Corte de Uniformização da Jurisprudência Infraconstitucional brasileira (o Superior Tribunal de Justiça) não se tem manifestado sobre $o$ assunto, considerando o enunciado $\mathrm{n}^{\circ} .7 \mathrm{de}$ sua Súmula. E ainda que se diga que a discussão se restringe à alternatividade ou cumulatividade dos requisitos, constituindo, portanto, matéria unicamente de direito, o fato é que o STJ ainda não se posicionou definitivamente sobre esse tema.

No entanto, a maioria dos tribunais inferiores pátrios já se posicionou favoravelmente à alternatividade, a exemplo das Cortes de Justiça de São Paulo, Minas Gerais e Paraná, senão veja-se:

PROVA. ÔNUS. INVERSÃO. PRESTAÇÃO DE SERVIÇO DE TELEFONIA. Presença de um dos requisitos previstos no Código de Defesa do Consumidor (hipossuficiência do consumidor ou verossimilhança da sua alegação). Suficiência. Finalidade de facilitar a defesa, gerando presunção que garanta ao consumidor integral acesso à justiça. Inversão do ônus decretada, determinando-se que a agravada apresente em juízo cópia das contas telefônicas mensais, desde a assinatura do contrato de prestação de serviço com o agravante. Recurso provido, para este fim." (TJSP; AI 962.074-00/7; São Paulo; Trigésima Câmara de Direito Privado; Rel. Des. Alfredo Fanucchi; Julg. 28/09/2005);

'MARQUES, Cláudia Lima; BENJAMIN, Antônio Herman de Vasconcellos e; MIRAGEM, Bruno. Comentários ao Código de Defesa do Consumidor. p. 183 ss. 
AGRAVO DE INSTRUMENTO. CONTRATO DE PRESTAÇÃO DE SERVIÇOS. INCIDÊNCIA DO CDC HIPOSSUFICIÊNCIA. INVERSÃO DO ÔNUS DA PROVA. DETERMINAÇÃO DE OFÍCIO. POSSIBILIDADE. É inequívoca a aplicabilidade do código do consumidor aos contratos de prestações de serviços. Para a inversão do ônus da prova, deve o juiz verificar no caso concreto a ocorrência dos requisitos alternativos, quais sejam, a verossimilhança da alegação ou a hipossuficiência do consumidor, bastando um deles para propiciar a inversão. (...)" (TJ-MG; AG 1.0145.06.351758-8/0011; Juiz de Fora; Décima Quarta Câmara Cível; Rel. Des. Elias Camilo Sobrinho; Julg. 27/09/2007; DJMG 30/10/2007);

AGRAVO REGIMENTAL. AGRAVO DE INSTRUMENTO PARCIALMENTE PROVIDO. I N V E R Ã O Ô N U D A P R O V . HIPOSSUFICIÊNCIA DO CONSUMIDOR. DECISÃO EM CONSONÂNCIA COM JURISPRUDÊNCIA DOMINANTE. INTELIGÊNCIA DO ARTIGO $6^{\circ}$, VIII, DO CÓDIGO DE DEFESA DO CONSUMIDOR. 1. É pacífico o entendimento jurisprudencial que presentes um dos requisitos indicados no inc. VIII, do at. $6^{\circ}$, do Código de Defesa do Consumidor, quais sejam, a verossimilhança da alegação ou a hipossuficiência, inverte-se o ônus da prova em favor da parte hipossuficiente. 2. Recurso desprovido." (TJ-PR; AgravReg 0439568-0/01; Barracão; Décima Oitava Câmara Cível; Rel. Juiz Conv. João Domingos Kuster Puppi; DJPR 14/12/2007; Pág. 56).

Os adeptos da corrente minoritária, por sua vez, defendem que os pressupostos da verossimilhança e da hipossuficiência são requisitos mínimos e que, em uma interpretação sistemáticoteleológica, ambos deveriam ser conjugados para que o consumidor obtivesse o direito à inversão.

Citando os Professores Antônio Gidi e Rodrigo Xavier Leonardo, Heitor Vitor Mendonça Sica, explica: ${ }^{6}$

$\mathrm{O}$ primeiro ilustra seu pensamento com a demanda de

'SICA, Heitor Vitor Mendonça. Questões velhas e novas sobre a inversão do ônus da prova (CDC, art. $6^{\circ}$, VIII), p. 57 ss. 
reparação de danos promovida por mendigo, alegando que seu automóvel estava estacionado em shopping center de luxo e foi roubado. O segundo invoca como exemplo a amparar sua tese ação indenizatória promovida por pessoa humilde, reclamando ter ficado doente por ingestão de alimentos em restaurante requintado e caro. Em ambos os casos, embora os demandantes ostentem hipossuficiência, suas pretensões baseiam-se em alegações inverossímeis, o que excluiria a inversão.

A seguir, discordando, comenta o autor:

Ao tratar da hipossuficiência, chegamos à conclusão de que seu reconhecimento pode recair apenas sobre determinados fatos (naqueles em que se verifica clara assimetria de informações entre fornecedor e consumidor), mas não sobre todas as circunstâncias ocorridas durante a relação de consumo.

Os exemplos dados por Gidi e Leonardo pecam por desconsiderar essa premissa. Entendemos que, no exemplo invocado pelo primeiro, o mendigo haveria de provar ser proprietário do veículo supostamente roubado (por meio de documento hábil) e de tê-lo estacionado no shopping center. Mas quanto aos demais fatos constitutivos de sua pretensão ressarcitória, não haveria obstáculo algum à inversão do ônus probatório.

$\mathrm{Na}$ situação criada pelo segundo autor referido, a pessoa humilde deveria provar apenas que esteve no restaurante refinado e lá fez uma refeição (por meio de recibo, nota fiscal, fatura de cartão de crédito ou testemunhas) porque, quanto ao mais, a inversão do ônus da prova poderia ser perfeitamente admissível.

$\mathrm{Na}$ dúvida, que prevaleça o critério mais favorável ao consumidor, qual seja o da alternatividade, em detrimento do da cumulatividade, até porque se harmoniza com a jurisprudência que se vem consolidando a respeito.

Vencido, pois, esse primeiro obstáculo, com a conclusão de que basta a presença de apenas um dos requisitos (verossimilhança das alegações do consumidor ou sua hipossuficiência) para autorizar o juiz a inverter o onus probandi, urge, agora, precisar cada um dos conceitos jurídicos indeterminados que aparecem no contexto do dispositivo legal em comento: a) verossimilhança; b) hipossuficiência; c) critério do juiz; d) regras ordinárias da 
experiência.

VEROSSIMILHANÇA: em linguagem corrente (extraída da wikipédia), "é o atributo daquilo que parece intuitivamente verdadeiro, isto é, o que é atribuído a uma realidade portadora de uma aparência ou de uma probabilidade de verdade, na relação ambígua que se estabelece entre imagem e idéia." A lei, por certo, incorporou esse sentido comum ao instituto, elegendo-o como uma das condições para que o juiz inverta o mencionado ônus. Então, tecnicamente, dá-se o mesmo, ou seja, se a alegação do consumidor, a critério do juiz, segundo as regras de experiência, aparenta ser a expressão da verdade real, considera-se preenchida aquela condição.

HIPOSSUFICIÊNCIA: é um aspecto da vulnerabilidade do consumidor, não se restringindo apenas à sua baixa capacidade econômica. Para Cecília Matos, em dissertação de mestrado apresentada à Faculdade de Direito da USP, a hipossuficiência “.... demonstra uma diminuição de capacidade do consumidor, não apenas no aspecto econômico, mas social, de informações, de educação, de participação, de associação, entre outros..."”, acrescentando que o CDC pretendeu "... tutelar tanto aquele que apresente alegações verossímeis como aqueles outros que, apesar de não verossímeis as suas alegações, sejam hipossuficientes e vulneráveis, segundo assim entenda o julgador com base em suas regras de experiência."

CRITÉRIO DO JUIZ: significa, primeiramente, juízo de valor por parte do magistrado, mas feito a partir de uma base lógica e objetiva de comparação, tal como na expressão "prudente arbítrio do juiz", onde a menção à prudência afasta a mera discricionariedade ou subjetividade do mesmo, o que, do contrário, violaria a ordem jurídica justa. Por outro lado, demonstra que a inversão é da espécie judicial (ope iudicis) e não ope legis, como explicado anteriormente.

REGRAS ORDINÁRIAS DA EXPERIÊNCIA: nada mais significa do que o conhecimento comum, adquirido com a realidade

'GRINOVER, Ada Pellegrini; BENJAMIN, Antônio Herman de Vasconcellos e; FINK, Daniel Roberto; FILOMENO, José Geraldo Brito; WATANABE, Kazuo; NERY JR., Nelson; DENARI, Zelmo. Código Brasileiro de Defesa do Consumidor. p. 795.

${ }^{8}$ Idem. 
prática da vida. Este conceito, aliás, antes de se incorporado pelo CDC, já constava do Código de Processo Civil, no seu art. 335, segundo o qual "Em falta de normas jurídicas particulares, o juiz aplicará as regras de experiência comum subministradas pela observação do que ordinariamente acontece e ainda as regras de experiência técnica, ressalvado, quanto a esta, o exame pericial." Exige-se do juiz, assim, "uma aguçada sensibilidade quanto à realidade mais ampla onde está contido o objeto da prova cuja inversão vai operar-se", como já proclamado pelo Superior Tribunal de Justiça (Resp. 140.097/SP, Rel. Min. CESAR ASFOR ROCHA, DJ 11.09.2000, p. 252).

Assim, pode-se dizer que, havendo fundada dúvida do magistrado (non liquet) a respeito dos fatos da causa, em matéria de relação consumerista, e sendo aparentemente verdadeiras as alegações do consumidor, ou for este hipossuficiente, tudo consoante o prudente arbítrio do juiz, calcado em sua experiência de vida, deverá ele inverter o ônus da prova. Eis uma interpretação razoável da regra contida no art. $6^{\circ}$, VIII do Código de Defesa do Consumidor.

Saliente-se, por oportuno, que para os próprios autores do anteprojeto do nosso atual CDC, no que tange à verossimilhança das alegações do consumidor - diferentemente do que acontece quando verificada a sua hipossuficiência -, não se dá propriamente uma inversão do onus probandi, senão veja-se:

O que ocorre, como bem observa Leo Rosenberg, éque o magistrado, com a ajuda das máximas de experiência e das regras de vida, considera produzida a prova que incumbe a uma das partes. Examinando as condições de fato com base em máximas de experiência, o magistrado parte do curso normal dos acontecimentos, e, porque o fato é ordinariamente a conseqüência ou o pressuposto de um outro fato, em caso de existência deste, admite também aquele como existente, a menos que a outra parte demonstre o contrário. Assim, não se trata de uma autêntica hipótese de inversão do ônus da prova. ${ }^{9}$

Por seu turno, a hipossuficiência, como acima mencionado, não

${ }^{9}$ IBDEM, p.p. $793 / 794$

Revista Esmat, Palmas, Ano 2, n 2, pag. 83 a 110 - jan/dez 2010 
se restringe tão-somente à condição econômica desfavorável do consumidor. Ela vai muito além disso. Para TIAGO CARDOSO ZAPATER, ${ }^{10}$ a hipossuficiência do consumidor se manifesta através de três espécies de vulnerabilidade: a) técnica, quando lhe faltarem conhecimentos sobre o produto ou serviço que está sendo adquirido ou contratado; b) jurídica, traduzida pela falta de conhecimentos do consumidor nas áreas jurídica e contábil, na hora, por exemplo, de comprar a prestações; c) sócio-econômica, resultante da posição do fornecedor no mercado.

Em verdade, essa é só uma das classificações possíveis, pois que nas incontáveis relações jurídicas sob comento, o consumidor podese ver em situações outras de vulnerabilidade.

De qualquer modo, tem-se mais presente que a hipossuficiência de que trata o dispositivo legal em apreço é, basicamente, técnica, ligada à posse de informações e conhecimentos específicos. Assim, mesmo uma pessoa afortunada pode ser considerada, em várias situações, um hipossuficiente, quando, por exemplo, adquire, para uso próprio, um avião que venha a apresentar um defeito estrutural. Neste caso, é claro que o consumidor terá muito mais dificuldade do que o fabricante para demonstrar que, de fato, se está diante de um defeito de construção do equipamento.

\subsection{Vulnerabilidade $\mathrm{x}$ hipossuficiência}

Note-se que hipossuficiência não se confunde com vulnerabilidade. Como já se disse anteriormente, a hipossuficiência é apenas um aspecto da vulnerabilidade. Então, pode-se dizer que todo consumidor é vulnerável, mas a recíproca não é verdadeira, isto é, nem todo consumidor é hipossuficiente.

É a própria lei $(8.078 / 1990)$ que determina ser o consumidor vulnerável, elencando esta máxima como um princípio, senão vejase:

Art. $4^{\circ}$ A Politica Nacional das Relações de Consumo

\footnotetext{
${ }^{10}$ OLIVEIRA, Alexandre Olavo Carvalho de. Direito do Consumidor: ônus da realização da prova e inversão do ônus da prova sob o paradigma do Estado Democrático de Direito. Disponível $\mathrm{em}:<\mathrm{http}: / / \mathrm{www}$.praetorium.com.br/?section=artigos\&id=63>. Acesso em: 2 out. 2008
} 
tem por objetivo o atendimento das necessidades dos consumidores, o respeito à sua dignidade, saúde $e$ segurança, a proteção de seus interesses econômicos, $a$ melhoria da sua qualidade de vida, bem como a transparência e harmonia das relações de consumo, atendidos os seguintes princípios:

$I$ - reconhecimento da vulnerabilidade do consumidor no mercado de consumo:

(...). Grifou-se.

Por uma opção do legislador, entende-se que o consumidor, no mercado de consumo, está sempre vulnerável. E isso, de fato, reflete a realidade, na medida em que ele não participa das etapas de produção dos bens e da organização dos serviços postos à sua disposição.

Todavia, embora vulnerável o consumidor, sua hipossuficiência deve ser demonstrada em cada caso, para efeito de inversão do ônus da prova.

Um bom exemplo é dado pelo Professor Heitor Sica, não sem antes ensinar que para cada fato probando deve ser feita a análise da presença ou não da mencionada hipossuficiência. Portanto, imagine-se uma “... demanda indenizatória ajuizada contra determinada companhia que fabrica cigarros, alegando o autor ter contraído câncer nos pulmões em decorrência do consumo prolongado desse produto, sem advertências do fornecedor acerca dos riscos do tabagismo causar dependência química e diversos males à saúde."

Ora, continua ele:

Para que a pretensão do consumidor seja acolhida, é necessário que fiquem devidamente demonstrados, pelo menos, os seguintes fatos:

a) que o consumidor efetivamente adquiria e consumia continuamente os cigarros fabricados pela empresa demandada;

b) que o consumidor desenvolveu o câncer;

c) que o câncer foi contraído em decorrência do tabagismo;

d) que a publicidade veiculada pelo fornecedor não alertou o consumidor acerca dos riscos advindos do consumo de cigarro.

O consumidor não é hipossuficiente para prova dos fatos a e b, acima enunciados. Quanto à prova do primeiro (a), 
ela não depende de quaisquer conhecimentos técnicos. Ao contrário, é o fornecedor quem não tem a menor chance de provar que o consumidor consumia cigarros de marca pertencente a outro fabricante. Não se pode dele esperar que arrole o balconista da padaria vizinha à casa do consumidor, para afirmar em juizo que ele comprava os cigarros de outra empresa. Já a prova do segundo (b) é ainda mais acessivel ao consumidor. Basta juntar cópia de exame laboratorial ou laudo subscrito por médico atestando a existência da moléstia.

Mas é natural que haja hipossuficiência do consumidor para prova do nexo entre tabagismo e câncer (fato c), bem como da inexistência de propaganda adequada que alerte dos riscos do produto para a saúde (fato d).

Adiante, ele explica que, nas hipóteses dos fatos "c" e "d", é natural que o fornecedor detenha conhecimentos técnicos muito mais vastos do que o consumidor, facilitando-lhe sobremaneira a produção da prova, para, afinal, concluir que “.... inversão do ônus da prova é limitada ao fato cuja prova dependa de conhecimentos específicos, detidos em maior grau pelo fornecedor em relação ao consumidor."

Demais disso, importante identificar quem pode ser consumidor na relação jurídico-material respectiva. Com efeito, antes de ser hipossuficiente em relação à prova de determinado fato do qual não detém o domínio das informações, é necessário que o sujeito dessa relação figure, realmente, como consumidor, sem o que não há falar em inversão do onus probandi.

A caracterização do consumidor é controversa, girando em torno da expressão "destinatário final", constante do art. $2^{\circ}$ do CDC, consoante o qual:

Art. $2^{\circ}$ Consumidor é toda pessoa fisica ou jurídica que adquire ou utiliza produtos ou serviço como destinatário final. Sublinhou-se.

Quem melhor esclarece sobre o assunto é a Ministra Fátima Nancy Andrighi, do Superior Tribunal de Justiça, expressis verbis:

De início, a doutrina se dividiu em duas teorias: a finalista (ou subjetiva) e a maximalista (ou objetiva).

"Ob. cit., pp. 53 e 54. 
A principal diferença entre elas decorre da circunstância de a doutrina finalista não considerar como consumidor a pessoa que utiliza um produto ou serviço na sua atividade profissional, ou seja, para a teoria finalista a pessoa que adquire um bem ou serviço com o intuito de lucro não é considerada consumidora.

A $2^{\mathrm{a}}$ Seção do STJ, no julgamento do CC 41.056/SP (DJ: 20/9/2004), em acórdão de minha relatoria, considerou como consumidora uma farmácia que celebrou contrato com sociedade empresária que administrava serviços de pagamento por meio de cartão de crédito (Visanet).

$\mathrm{Na}$ oportunidade, ao adotar a teoria maximalista, fiz questão de ressaltar a vulnerabilidade da farmácia, e o fato de que nem ela nem o contrato tinham porte econômico expressivo.

Já no julgamento do REsp 541.867 (julgado em 10/11/2004), rel. p/ acórdão Min. Barros Monteiro, a $2^{\mathrm{a}}$ Seção do STJ adotou a teoria finalista e entendeu não haver relação de consumo entre uma sociedade empresária revendedora de tintas e uma administradora de cartão de crédito. Também nessa oportunidade, houve discussão quanto à hipossuficiência da revendedora de tintas.

Como se vê, a questão é polêmica não somente na doutrina como também na jurisprudência.

Mas, independentemente do posicionamento que vier a ser pacificado no STJ, tenho que nunca poderá ser esquecido o princípio do $\mathrm{CDC}$, talvez o maior, de reconhecimento da vulnerabilidade do consumidor no mercado de consumo (art. $4^{\circ}$, I). Ou seja, o CDC sempre deverá ser interpretado de forma teleológica, e os seus dispositivos somente serão aplicados para proteger a parte mais fraca da relação jurídica (o vulnerável, hipossuficiente). ${ }^{12}$

No entender da eminente Ministra Nancy Andrighi, como visto, ainda que a pessoa física ou jurídica adquira bens ou serviços para o incremento de sua atividade empresarial, em algumas situações ela será considerada consumidora, justamente quando estiver na

\footnotetext{
${ }^{12}$ ANDRIGHI, Fátima Nancy. O CDC e o STJ. Jus Navigandi, Teresina, ano 11, n. 1236, 19 nov. 2006. Disponivel em <http://jus2.uol.com.br/doutrina/texto.asp?id=9176>. Acesso $\mathrm{em} 06$ abr. 2007.
} 
posição de hipossuficiência a que se fez referência acima. Em outras palavras, toda vez que o contratante se encontrar nessa posição de vulnerabilidade em relação ao fornecedor, deverá ser considerado consumidor, adotando-se a teoria maximalista. A adoção de uma ou outra teoria pelo julgador, portanto, dependeria do exame das circunstâncias envolvidas em cada caso concreto.

\section{MOMENTO DE INVERTER O ONUS PROBANDI}

Já foi dito que a verossimilhança das alegações do consumidor não corresponde propriamente a uma hipótese de inversão do ônus da prova. Na verdade, essa operação racional consistente em partir de um indício para afirmar a existência de outro fato (este relevante para a solução do litígio), apoiando-se nas regras de experiência, por meio das quais se podem formular presunções comuns ou do homem (praesumptiones hominis), o que pode acontecer em qualquer processo, conforme autorizado pelo art. 335 de nossa Lei Adjetiva Civil. $^{13}$

Tais regras de experiência, hauridas da realidade prática, supririam a imprescindibilidade da prova direta sobre determinado fato, afastando, de certa maneira, a máxima de que "o que não está nos autos não está no mundo".

Cândido Rangel Dinamarco aborda o assunto, mutatis mutandis, sob o tema da prova suficiente, pontificando com a eloqüência que lhe é peculiar:

Nunca os encargos probatórios devem ser tão pesados para uma das partes, que cheguem ao ponto de dificultar excessivamente a defesa de seus direitos. Considera-se cumprido o onus probandi quando a instrução processual houver chegado à demonstração razoável da existência do fato, sem os extremos da exigência de uma certeza absoluta que muito dificilmente se atingirá. A certeza, em termos absolutos, não é requisito para julgar. Basta que, segundo o juizo comum do homo

\footnotetext{
${ }^{13}$ Art. 335. Em falta de normas jurídicas particulares, o juiz aplicará as regras de experiência comum subministradas pela observação do que ordinariamente acontece e ainda as regras da experiência técnica, ressalvado, quanto a esta, o exame pericial.
} 
medius, a probabilidade seja tão grande que os riscos de

erro se mostrem suportáveis. Probabilidade é a convergência de elementos que conduzem razoavelmente a crer numa afirmação, superando a força de convicção dos elementos divergentes desta (...). Exigir certeza absoluta seria desconhecer a falibilidade humana. $O$ juiz que pela obsessão da verdade considerasse inexistentes os fatos afirmados, somente porque algum leve resquício de dúvida ainda restasse em seu espirito, em nome dessa ilusória segurança para julgar estaria com muito mais freqüência praticando injustiças do que fazendo justiça (....). ${ }^{14}$

Assim sendo, a verdadeira inversão do ônus da prova, subsumida no preceito do art. $6^{\circ}$, VIII do CDC, representando uma inovação no sistema jurídico, é a decorrente da hipossuficiência do consumidor, para onde se devem mover as preocupações do intérprete.

\subsection{Regra de julgamento ou de procedimento?!}

Não havendo mais dúvida de que o magistrado terá de voltar sua atenção sobre saber se o consumidor é ou não hipossuficiente para tal e qual fato determinado cuja prova seja relevante produzir, deverá ele fazer-se uma pergunta crucial, seguramente a mais importante de todo este estudo, qual seja: afinal, a inversão do ônus da prova é regra de julgamento ou de procedimento? A resposta a essa pergunta identificará o momento da inversão (quando ela deverá ser levada a efeito?).

"De um lado, há autores que apregoam que as regras de distribuição e inversão do ônus da prova seriam regras de julgamento, aplicáveis apenas no momento em que fosse proferida a decisão de mérito, tendo em vista todo o conjunto probatório existente nos autos. Somente nesse momento teria o juiz condições de saber se a prova colhida é suficiente para formar sua conviç̧ão, e somente em caso negativo, ser-lhe-ia lícito recorrer às regras de

${ }^{14}$ DINAMARCO, Cândido Rangel. Instituições de Direito Processual Civil, p. 81-82. 
ônus da prova (incluída, aqui, a inversão para as relações de consumo, quando fosse o caso). Ademais, o fornecedor saberia, de antemão, do risco de inversão, de modo que não poderia invocar em seu benefício a própria omissão em produzir todas as provas necessárias a se desincumbir do seu ônus probatório ordinário e do ônus eventualmente decorrente da inversão."

"De outro lado, há aqueles que sustentam a necessidade de o juiz, no curso do processo, informar expressamente às partes, ao menos do risco de inversão, a tempo de aquela que sairia prejudicada disso produzisse as provas necessárias a se desincumbir desse 'novo' ônus que, pelas regras normais do art. 333 do CPC, não teria. Assim, a inversão do ônus da prova estaria insculpida em uma regra de procedimento, e, como tal, sua aplicação deve se dar ao longo de seu desenvolvimento (preferencialmente na fase saneadora). Invocamse, para tanto, modernas teorias processuais, baseadas na idéia de 'cooperação processual', e que implicariam a necessidade de um. diálogo aberto entre o juiz e as partes, sem riscos de surpresas para essas últimas. A ausência de aviso, durante o curso do processo, de que uma parte seria beneficiada pela inversão do ônus probatório faria com que a parte adversa não produzisse todas as provas que estavam a seu alcance, o que caracterizaria cerceamento de defesa." $" 16$

Passados quase 20 (vinte) anos da promulgação do Código de Defesa do Consumidor, ainda não há consenso a respeito. Percebase, porém, que, em nome daquela cooperação processual, muitos autores de nomeada têm entendido que a aplicação do art. $6^{\circ}$, VIII do CDC não se pode dar de outro modo se não como regra de procedimento, sob color de que, do contrário, haveria inevitavelmente cerceamento de defesa para a parte a quem, inicialmente, não incumbisse tal ônus, segundo as regras ordinárias de distribuição do onus probandi (leia-se: CPC 333).

Para esses doutrinadores, portanto, uma vez encarada a inversão do ônus probatório como regra de julgamento, alguém sempre iria ser "pego de surpresa", sem possibilidade de se defender a contento,

\footnotetext{
${ }^{15}$ SICA, Heitor Vitor Mendonça. Questões velhas e novas sobre a inversão do ônus da prova (CDC, art. 6 $6^{\circ}$, VIII), p. 59.

${ }^{16}$ Idem.
} 
o que violaria o princípio constitucional da ampla defesa, corolário do devido processo legal.

Para eles, então, necessário que o juiz, na fase de saneamento do processo, anuncie a possibilidade de inversão do ônus da prova, dando tempo para que a parte desfavorecida possa requerer a produção da prova que, a rigor, caberia à contraparte, a exemplo do que usualmente ocorre em relação ao anúncio do julgamento antecipado da lide, quando a matéria é só de direito ou, sendo de direito e de fato, o juiz entender que não há necessidade de produzir prova em audiência, ficando preclusa a questão relativa ao cerceamento de defesa em caso de não interposição de agravo.

Todavia, ousamos discordar desses doutos entendimentos. Com efeito, há três argumentos que se colocam como entrave a essa posição doutrinária, sufragando, assim, a tese contrária, ou seja, da regra de julgamento. $\mathrm{O}$ primeiro deles é que tal anúncio não tem amparo legal; não há previsão, seja no CDC seja no CPC, dessa possibilidade, o que traduz a opção legislativa pela inversão como regra de julgamento, a ser avaliada na sentença, depois de encerrada toda a fase instrutória. O segundo, consiste exatamente em que as regras de distribuição do ônus da prova, previstas no art. 333 do Código de Processo Civil, estão, nesse ponto, derrogadas pela legislação especial consumerista, de maneira que, uma vez modificado o sistema de realização da prova, não pode a parte desfavorecida alegar qualquer surpresa ou suposta violação à ampla defesa, assumindo, assim, o ônus de produzir determinada prova que, a princípio, seria da parte adversa, mas cuja inversão poderia o juiz determinar.

Esses dois primeiros argumentos são comumente lembrados. Mas há um terceiro, aliás, o mais forte, que, entretanto, se costuma olvidar, talvez por conveniência ou, mesmo, conivência. É o fato de que somente o consumidor pode ser favorecido com a inversão do ônus probatório. $\mathrm{O}$ fornecedor, nunca. $\mathrm{O}$ que se viu em linhas precedentes, é que nem sempre o consumidor é hipossuficiente em relação à prova de determinado fato. Em algumas situações, o fornecedor é que é hipossuficiente em relação ao consumidor. Porém, a lei só confere a este último a benesse da inversão. $\mathrm{O}$ fornecedor, assim, ainda que hipossuficiente em determinado caso, não se pode valer do art. $6^{\circ}$, VIII do CDC em seu prol. A solução, 
portanto, é considerar que incumbe a prova ao consumidor quando ele não for hipossuficiente (nos moldes do CPC 333), podendo ser invertida em seu favor (e só dele) quando o for, não gozando desse benefício o fornecedor.

Isso se dá, porque o consumidor é que é considerado vulnerável, e não o fornecedor ( $\left.\mathrm{CDC} 4^{\circ} \mathrm{I}\right)$. Da mesma forma em que não existe o princípio da ampla acusação no processo penal (e sim o da ampla defesa), não existe, também, o princípio da proteção ao fornecedor, e sim, o da proteção ao consumidor. Não há motivo, portanto, in casu, para se preocupar com quem está mais bem posicionado no mercado de consumo. O sentido da lei, pois, aqui, lembrando o disposto no art. $5^{\circ}$ da Lei de Introdução ao Código Civil, ${ }^{17}$ se dirige a proteger o consumidor, e não o fornecedor, de maneira que inconstitucional (por não realizar o princípio da defesa do consumidor) é a prática que cria um obstáculo à defesa da parte menos favorecida no mercado de consumo, e não o contrário.

Saliente-se, outrossim, que o juiz, para identificar a hipossuficiência do consumidor, a exemplo da verossimilhança, também se utiliza, segundo o seu prudente arbítrio, das regras ordinárias de experiência, de maneira que o fornecedor precisa ficar atento para reconhecer quando, ele próprio, estiver em melhores condições de produzir a prova, um sinal claro de que o consumidor é hipossuficiente no caso e de que o juiz inverterá o ônus probatório por ocasião da sentença. Aliás, esta forma de visualizar o problema vai ao encontro da boa-fé objetiva, que é o que espera do fornecedor, elo mais forte da relação de consumo.

Entendemos, assim, que não há falar, no que concerne à inversão do ônus da prova, em possibilidade de conflito, no caso concreto, entre os princípios da defesa do consumidor (CF $170 \mathrm{~V})$, de um lado, e do devido processo legal (CF $5^{\circ}$ LIV) e ampla defesa $\left(C F 5^{\circ} \mathrm{LV}\right)$, do outro, razão porque não se exigirá do juiz qualquer sopesamento de interesses nesse sentido. É algo, portanto, que se resolve no plano abstrato das normas, adotando-se a tese da regra de julgamento, por ser uma opção do legislador com o objetivo de realizar o princípio da defesa do consumidor.

\footnotetext{
${ }^{17} \mathrm{Art} .5^{\circ} \mathrm{Na}$ aplicação da lei, o juiz atenderá aos fins sociais a que ela se dirige e às exigências do bem comum.
} 
Todavia, pensamos que - e essa é a inovação aqui proposta o magistrado não pode se furtar a deferir eventual PEDIDO DO FORNECEDOR de anunciar a possibilidade de inversão do onus probandi quando houver fundado receio de que ele assim 0 fará na sentença. O que não pode acontecer, como muitos defendem, é tornar isso um dever do juiz, em detrimento do consumidor, de maneira que, se o reitor do feito, de ofício, não anunciar a possibilidade de inversão, eventual sentença que valorasse a prova, invertendo-lhe o ônus, estaria eivada de nulidade.

Não. Não pode ser assim. Com efeito, o juiz não está obrigado a anunciar a possibilidade de inverter o ônus probatório. Mas, se for instado a fazê-lo PELO FORNECEDOR, sobre determinado fato relevante da causa, $\mathrm{e}$ houver plausibilidade no pleito, consubstanciada na probabilidade de que venha a aplicar a inversão na sentença, aí sim, não pode o magistrado se furtar a tanto, sob pena de violação ao due process of law, pois que o processo é meio de realização da justiça e isso é perfeitamente razoável, dando ensanchas à otimização de todos os princípios envolvidos.

Embora não haja consenso a respeito, como se disse, a jurisprudência tem-se inclinado por encarar a inversão do ônus probatório como regra de julgamento, como se vê, paradigmaticamente, da ementa do seguinte julgado do STJ, abaixo colacionada:

RECURSO ESPECIAL. CIVIL E PROCESSUAL CIVIL. RESPONSABILIDADE CIVIL. INDENIZAÇÃO POR DANOS MATERIAIS E COMPENSAÇÃO POR DANOS MORAIS. CAUSA DE PEDIR. CEGUEIRA CAUSADA POR TAMPA DE REFRIGERANTE QUANDO DA ABERTURA DA GARRAFA. PROCEDENTE. OBRIGAÇÃO SUBJETIVA DE INDENIZAR. SÚMULA 7/STJ. PROVA DE FATO NEGATIVO. SUPERAÇÃO. POSSIBILIDADE DE PROVA DE AFIRMATIVA OU FATO CONTRÁRIO. INVERSÃO DO ÔNUS DA PROVA EM FAVOR DO CONSUMIDOR. REGRA DE JULGAMENTO. DOUTRINA E JURISPRUDÊNCIA. ARTS. 159 DO CC/1916, 333, I, DO CPC E 6. ${ }^{\circ}$, VIII, DOCDC. 
- Se o Tribunal a quo entende presentes os três requisitos ensejadores da obrigação subjetiva de indenizar, quais sejam: (i) o ato ilícito, (ii) o dano experimentado pela vítima e (iii) o nexo de causalidade entre o dano sofrido e a conduta ilícita; a alegação de violação ao art. 159 do CC/1916 (atual art. 186 do CC) esbarra no óbice da Súmula n. ${ }^{\circ} 7$ deste STJ.

- Tanto a doutrina como a jurisprudência superaram a complexa construção do direito antigo acerca da prova dos fatos negativos, razão pela qual a afirmação dogmática de que o fato negativo nunca se prova é inexata, pois há hipóteses em que uma alegação negativa traz, inerente, uma afirmativa que pode ser provada. Desse modo, sempre que for possível provar uma afirmativa ou um fato contrário àquele deduzido pela outra parte, tem-se como superada a alegação de 'prova negativa', ou 'impossível'.

- Conforme posicionamento dominante da doutrina e da jurisprudência, a inversão do ônus da prova, prevista no inc. VIII, do art. $6 .^{\circ}$ do CDC é regra de julgamento. Vencidos os Ministros Castro Filho e Humberto Gomes de Barros, que entenderam que a inversão do ônus da prova deve ocorrer no momento da dilação probatória.

Recurso especial não conhecido.” (REsp 422.778/SP, Rel. Ministro CASTRO FILHO, Rel. p/ Acórdão Ministra NANCY ANDRIGHI, TERCEIRA TURMA, julgado em 19/06/2007, DJ 27/08/2007 p. 220). Grifouse.

Finalmente, chama-se à atenção para o fato de que, em sendo regra de julgamento, a inversão do onus probandi, o próprio tribunal pode fazê-lo, se discordar do posicionamento adotado pelo juiz, caso em que estará modificando a sentença, o que é perfeitamente possível, por se encontrar, ainda, em instância ordinária (a segunda), que admite, como cediço, o reexame de provas.

Pode, assim, entender o tribunal "ad quem" que o juiz " $a$ quo" valorou mal determinada prova ou as circunstâncias fáticas de determinado ponto da demanda que daria ensejo, ou não, à inversão do ônus probatório, tal como uma imprecisa avaliação sobre a hipossuficiência da parte. 


\section{CONCLUSÃO}

Para encerrar, pode-se concluir, ao final deste trabalho, que o instituto da inversão do ônus da prova, ao invés de violar o princípio da igualdade, muito ao contrário, robustece-o dentro de nosso ordenamento jurídico, na medida em que ajuda a igualar o consumidor, parte vulnerável nas relações consumeristas, frente ao fornecedor, parte mais forte no mercado de consumo. O mesmo se diga com relação ao devido processo legal, de que é corolário o princípio da ampla defesa, os quais não sofrem qualquer arranhão, como visto, se a inversão do ônus probatório for encarada como regra de julgamento (com a ressalva do atendimento a pedido específico formulado pelo fornecedor, nos termos propostos em linhas pretéritas).

Finalmente, não se deve preocupar o magistrado, aqui, com o princípio da proporcionalidade, implícito na nossa Constituição Cidadã, na verdade um critério de interpretação e aplicação do direito, quando se está no dilema de sopesar interesses em conflito, pois que entendemos não haver, relativamente à inversão do onus probandi, qualquer conflito em jogo, resolvendo-se a otimização do princípio da defesa do consumidor no plano abstrato mesmo, sem nenhuma ingerência mais relevante nos outros princípios em tablado, aparecendo a inversão do ônus da prova como um eficaz instrumento de sua realização (do princípio da defesa do consumidor) como direito fundamental dos brasileiros.

\section{REFERÊNCIAS BIBLIOGRÁFICAS}

ANDRIGHI, Fátima Nancy. O CDC e o STJ. Jus Navigandi, Teresina, ano 11, n. 1236, 19 nov. 2006. Disponível em <http://jus2.uol.com.br/doutrina/texto.asp?id=9176>. Acesso em 06 abr. 2007.

BARROSO, Luís Roberto. O Controle de Constitucionalidade no Direito Brasileiro. 2. ed. São Paulo: Saraiva, 2007.

DIDIER JR., Fredie (Org.). Leituras Complementares de Processo Civil. Salvador: Jus PODIVM, 2008, p. 25 ss. 
DINAMARCO, Cândido Rangel. Instituições de Direito Processual Civil. 4. ed. São Paulo: Malheiros, 2004.v. 3.

GRINOVER, Ada Pellegrini; BENJAMIN, Antônio Herman de Vasconcellos e; FINK, Daniel Roberto; FILOMENO, José Geraldo Brito; WATANABE, Kazuo; NERY JR., Nelson; DENARI, Zelmo. Código Brasileiro de Defesa do Consumidor. 8. ed. Rio de Janeiro: Forense, 2004.

MARQUES, Cláudia Lima; BENJAMIN, Antônio Herman de Vasconcellos e; MIRAGEM, Bruno. Comentários ao Código de Defesa do Consumidor. 2. ed. São Paulo: RT, 2006, p. 183 ss.

MORAES, Alexandre de. Direito Constitucional. 17. ed. São Paulo: Atlas, 2005.

OLIVEIRA, Alexandre Olavo Carvalho de. Direito do Consumidor: ônus da realização da prova e inversão do ônus da prova sob o paradigma do Estado Democrático de Direito. Disponível em: <http://www.praetorium.com.br/?section=artigos $\&$ id $=63>$. Acesso em: 2 out. 2008.

SICA, Heitor Vitor Mendonça. Questões velhas e novas sobre a inversão do ônus da prova (CDC, art. $6^{\circ}$, VIII). Revista de Processo (RT), São Paulo, v. 146, p. 57 ss, 2007.

KRIGER FILHO, Domingos Afonso. Inversão do ônus da prova: regra de julgamento ou de procedimento? Revista de Processo (RT), São Paulo, v. 138, p. 276, ago. 2006. 